\title{
Long-term Monitoring of the Environmental Impact of a Refugee Camp Based on Landsat Time Series: The Example of Deforestation and Reforestation Dur- ing the whole Lifespan of the Camp Lukole, Tanzania
}

\author{
Sebastian Langer, Dirk Tiede and Fritjof Lüthje \\ Department of Geoinformatics - Z_GIS, University of Salzburg, Austria · langerse@stud.sbg.ac.at
}

Short paper

\begin{abstract}
This study deals with the long-term monitoring of the environmental impact of the refugee camp Lukole, Tanzania. Based on high resolution (HR) satellite time series of different Landsat sensors, the whole lifespan of the camp is covered, starting before the camp was established (1994) until seven years after the dismantling (2015). A fully automated preclassification approach for different Landsat sensors was applied, and the results were integrated into a post-classification object-specific change comparison to quantify de- and reforestation processes during this time. The second part of the study will focus on different visualization methods to display the changes throughout the whole study area over time.
\end{abstract}

\section{Introduction}

In 2014, about 51.2 million persons were forcibly displaced worldwide, 16.7 million of which were refugees. This marks a new climax within the last decade and follows the trend of the previous years (UNHCR 2015). Refugee camps often have significant impacts on the surrounding environment. This study deals with issues of deforestation and reforestation in the area of the Lukole refugee camp, Tanzania. The long-term monitoring is based on a high resolution (HR) series of different Landsat sensors, which covers the whole period prior to the establishment of the camp until the dismantling more than 20 years later. The camp was established in 1994 by the United Nations High Commissioner for Refugees (UNHCR) for refugees, displaced by the conflict between Hutu and Tutsi in 1993 and 1994 from Rwanda and Burundi (GIADA et al. 2003). At its maximum extent in the year 2000, the camp area covered about $13 \mathrm{~km}^{2}$ and counted more than 130,000 people. The number of refugees then declined steadily until the camp was finally dismantled in 2008 (STÄNGEL et al. 2014). Refugee camps have an undeniable impact on the environment, which has been investigated in a number of articles and studies: KAKONGE 2000, NDYESHUMBA 2000, HAGENLOCHER et al. 2012, STÄNGEL et al. 2014 to name but a few. In Tanzania, one of the main refugee-induced impacts on the environment was the gathering of wood for construction or fire wood, resulting in deforestation of the surrounding areas. As a countermeasure, the UNHCR planted about 14 million tree seedlings in Northern Tanzania since 1995 (UNHCR 2008). This article addresses the question of how an automated pre-classification

GI_Forum - Journal for Geographic Information Science, 1-2015.

(C) Herbert Wichmann Verlag, VDE VERLAG GMBH, Berlin/Offenbach. ISBN 978-3-87907-558-4.

(C) ÖAW Verlag, Wien. ISSN 2308-1708, doi:10.1553/giscience2015s434. 
method and following change analysis can be of help to detect these environmental changes.

\section{Methodological Approach}

The analysis is based on satellite imagery from the Landsat-missions' archive. This allows the whole time range to be covered, from prior to the construction of the camp until today. The study area is determined based on a literature research about the action radius of refugees plus a buffer to visualize the change concerning non-impacted areas. NDYESHUMBA (2000) states that damage to the vegetation is clearly visible within a two-kilometre radius. The damage decreases with distance to the camp and becomes diffuse. BLOESCH (2001) describes that refugees would also collect and cut wood within a radius of 10 kilometres and more. Therefore, a buffer of 16 kilometres around the maximum extent of the camp (the extent is defined based on a VHR data analysis by STÄNGEL et al. 2014) has been calculated and used as a bounding box. The archive of the USGS EarthExplorer (earthexplorer.usgs.gov) reveals more than 40 scenes, in which the camp is almost or completely unobstructed by clouds or cloud shadows. The earliest scene dates back to December 1990. The most recent scene was recorded in January 2015. The study area is located close to the equator ( $\sim 2.6^{\circ}$ South), hence oscillation of the intertropical convergence zone (ITCZ) is the main driver of rainfall. In general, there are two dry seasons in May/June and September/October. This results in phenological differences throughout the course of one year. The environmental changes have proven to be best observable during the rainy season. The preclassification was calculated for all 40 scenes, but due to the phenological differences only 6 time steps in 5-year intervals have been chosen for the change analysis. Additional information, like occurrence of riparian vegetation, was extracted from dry season scenes. The selected pre-classification method is fully automatic, including pre-processing and preclassification using the spectral knowledge-based, multi-sensor Satellite Image Automatic Mapper (SIAM, BARALDI et al. 2010). Pre-processing consists of correction to top-ofatmosphere (TOA) reflectance, whereas SIAM automatically produces a multitude of preclassification results based on colour quantifications. This study mainly uses two output data sets of the SIAM pre-processing: (1) a pre-classification of 33 classes (see figure 1), defined to be detectable throughout numerous optical satellite sensors and thus highly suitable for long-term time series (change analyses) gathered by different Landsat satellites, and (2) an automatically generated greenness index. Based on these pre-classifications, the time series were analysed in an object-based change detection (OBCD) process to analyse trends of vegetation decrease and increase through time.

\section{$3 \quad$ Preliminary Results}

After the exploratory analysis of the data, combined with the knowledge revealed from the literature about the maximum extent of the camps, the time of dismantling and the reforestation efforts, two conclusions could be drawn. Firstly, the deforestation occurred mainly between 1994 (construction of camp) and 2008 (dismantling of camp); secondly, ascertainable reforestation tendencies began around the year 2000 (maximum extent of the camp). Figure $2 \& 3$ show these tendencies. These two maps are the result of the OBCD of the automatically produced greenness indices of the respective scenes. The pre-classification 
results are in addition particularly useful for the generation of cloud- and cloud shadow masks and a deeper analysis of the changes in vegetation intensities through the years.

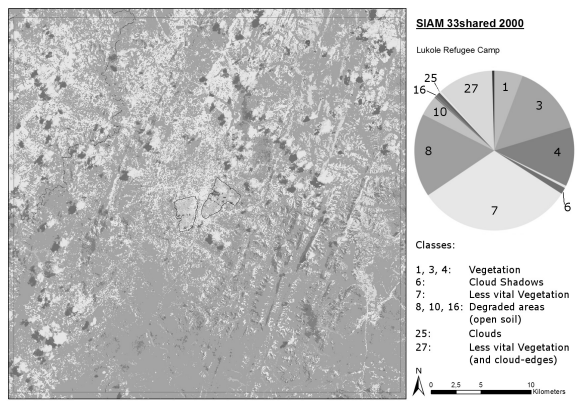

\section{Fig. 1:}

Example for a pre-classification result of one Landsat 7 scene (21 April 2000)

The development that can be observed in figure 2 shows the degradation of the natural vegetation around the camps. The scattered decrease towards the edges of the study area and the large patch (decrease 1995-2000) to the east are mainly due to agricultural activities and phenological differences. The same holds true for the larger part of the 'increase 20002005 ' east of the camps and the heterogeneous areas towards the north-west and south west in figure 3. The few changes in the time between 2010 and 2015 indicate that the greatest part of the reforestation was already completed prior to 2010 .



Fig. 2: Greenness development 1990-2005

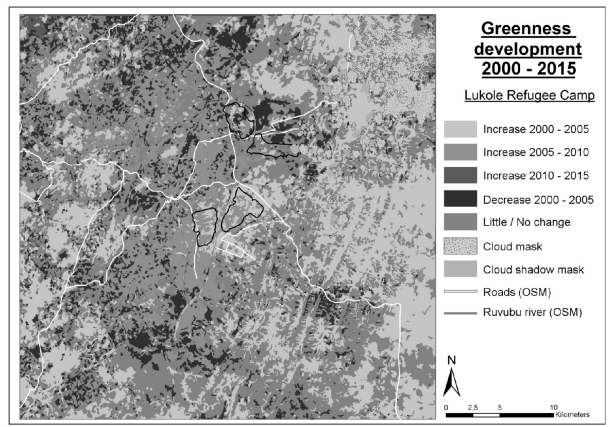

Fig. 3: Greenness development 2000-2015

\section{Discussion and Outlook}

The main challenges for this study were the differences in the phenology of the chosen images; the results were influenced by the variances in the rainfall between the years. The overall problem was the acquisition of suitable datasets for the timespan of more than 20 years, covering three different sensors (Landsat 5, 7, and 8). Not only the seasonal differences, but also cloud coverage in the area made many scenes unusable for the analysis. The chosen methodology for a full automatic pre-processing proved to be suitable for a quick analysis of the time series, reducing calculation time. In addition, it is parameter-free (no samples, no thresholds to be determined) since it relies on decision rules based on a physical model. Therefore, comparable results of large amounts of data from different sen- 
sors are produced in a timely manner (few minutes per scene on a standard PC). Upcoming work will include further pre-classification results into the OBCD, which up to now was solely based on the greenness index. This is expected to further improve the results. Additionally, different geovisualization techniques will be compared to enhance the readability of the complex content of change maps over several years. The results of this study are used to analyse the impact of refugee camps on the environment in the area, to evaluate and monitor the reforestation efforts by the UNHCR. In addition, it gives a unique retrospective view of the development of the camp more than 20 years ago.

\section{Acknowledgements}

The research has received funding from the Austrian Research Promotion Agency (FFG / ASAP programme) within the project EO4HumEn (contract no: 840081) and from the European Commission (EC) within the FP7 project G-SEXTANT (contract n: 312912).

\section{References}

Baraldi, A., Durieux L., Simonetti, D., Conchedda, G., Holecz, F. \& Blonda P. (2010), Automatic spectral rule-based preliminary classification of radiometrically calibrated SPOT-4/-5/IRS, AVHRR/MSG, AATSR, IKONOS/QuickBird/OrbView/GeoEye and DMC/SPOT-1/-2 imagery - Part I: System design and implementation. IEEE Trans. Geosci. Remote Sensing, 48 (3), 1299-1325.

Bloesch, U. (2001), The use of fire in the environmental rehabilitation on the sites of a former refugee camp at Benaco, Tanzania. Schweiz. Z. Forstwes. 152, 377-382.

GiadA, S., De Groeve, T., Ehrlich, D. \& Soille, P. (2003), Information extraction from very high resolution satellite imagery over Lukole refugee camp, Tanzania. Int. J. Remote Sens. 24, 4251-4266. doi:10.1080/0143116021000035021.

Hagenlocher, M., LANG, S. \& TIEDE, D. (2012), Integrated assessment of the environmental impact of an IDP camp in Sudan based on very high resolution multi-temporal satellite imagery. Remote Sens. Environ., 126, 27-38. doi:10.1016/j.rse.2012.08.010.

KAKONGE, J. O. (2000), A review of refugee environmental-oriented projects in Africa: a case for environmental impact assessment. Impact Assess. Proj. Apprais., 18, 23-32. doi: $10.3152 / 147154600781767565$.

NdyeshumbA, P. (2000), The Use of Remote Sensing for Environmental Impact Assessment and determination of the are affected by refugees in Ngara District, North Western Tanzania. Int. Arch. Photogramm. Remote Sens., 33, 981-984.

StÄngel, M., Tiede, D., Luethje, F., FÜreder, P. \& LANG, S. (2014), Object-based image analysis using VHR satellite imagery for monitoring the dismantling of a refugee camp after a crisis - the case of Lukole, Tanzania. In: GI_Heidelberg: Forum '14. Proceedings of the Geoinformatics Forum Salzburg. Wichmann, Berlin/Offenbach.

UNHCR (2008), UNHCR prepares transition ahead while camps are closing (WWW Document). UNHCR. http://www.unhcr.org/4857de172.html (30.1.15).

UNHCR (2015), Mid-year Trends 2014. http://www.unhcr.org/54aa91d89.html (30.1.15). 